\title{
IMPACTOS NA FORMAÇÃO DOCENTE: PERCEPÇÕES DE UM GRUPO DE COORDENADORAS DE ÁREA DO PIBID
}

\author{
Jane Herber ${ }^{1}$, Cristiane Antonia Hauschild ${ }^{2}$, Adriana Magedanz ${ }^{3}$, Flávia Zanatta ${ }^{4}$, \\ Márcia Solange Volkmer ${ }^{5}$
}

Resumo: Ao entender a necessidade de investir na formação docente com o intuito de qualificar a educação básica em âmbito nacional, o Ministério da Educação (MEC), por meio da Coordenação de Aperfeiçoamento de Pessoal de Nível Superior (CAPES), lança, em 2007, o Programa Institucional de Bolsa de Iniciação à Docência (PIBID). Desde então, o PIBID vem se firmando como política pública de formação docente e aproximando universidades e escolas para a formação qualificada de professores. Nesse sentido, este artigo objetiva socializar o resultado de uma pesquisa qualitativa realizada com as coordenadoras de área do PIBID de uma Instituição de Nível Superior Comunitária, localizada no Vale do Taquari/RS. O enfoque está relacionado aos impactos do PIBID na formação inicial dos licenciandos de acordo com as percepções dos entrevistados, que responderam a um questionário semiaberto. Para a análise dos dados foi utilizada a metodologia da análise textual discursiva. Os resultados revelam aspectos positivos do Programa no que diz respeito à formação inicial, tendo como destaque a prática docente evidenciada pelas ações desenvolvidas pelos bolsistas de iniciação à docência quanto a planejamento, metodologias e reconhecimento de realidades diferenciadas dos espaços escolares envolvidos, além de apontar para a necessidade de sua continuidade.

Palavras-chave: Formação. Docência. PIBID. Bolsista. Licenciatura.

1 Doutoranda do PPG Educação em Ciências: Química da Vida e Saúde - UFRGS. Professora da Universidade do Vale do Taquari - Univates. Coordenadora de Área de Gestão em Processos Educacionais do PIBID/Univates.

2 Doutora em Educação em Ciências e Matemática. Professora da Universidade do Vale do Taquari Univates. Coordenadora Institucional do PIBID/Univates.

3 Doutoranda do PPG em Ensino da Universidade do Vale do Taquari - Univates. Professora de Matemática da Universidade do Vale do Taquari - Univates. Coordenadora de Área do Subprojeto Interdisciplinar PIBID/Univates.

4 Doutoranda do PPG em Ensino da Universidade do Vale do Taquari - Univates. Professora de Língua Portuguesa e Língua Espanhola da Universidade do Vale do Taquari - Univates. Coordenadora de Área do Subprojeto Letras Português PIBID/Univates.

5 Doutora em História. Professora da Universidade do Vale do Taquari - Univates. Coordenadora de Área do Subprojeto História PIBID/Univates. 


\title{
IMPACTS IN THE TEACHING TRAINING: PERCEPTIONS FROM A GROUP OF SUBJECTS' COORDINATORS OF THE PIBID
}

\begin{abstract}
Acknowledging the necessity to invest in the teacher training with the aim to qualify the basic education in the national level, the Ministry of Education (MEC), by means of the Coordination of Improvement of Higher Education Personnel (CAPES), launched the Institutional Program of Teaching Initiation Scholarship (PIBID) in 2007. Thenceforth, the PIBID has been establishing itself as public policy of teacher training and bringing together colleges and schools in the pursuit of the qualified training of the teachers. In this sense, this paper targets the publication of the results of a research carried on with the subjects' coordinators of the PIBID in a community higher level institution, located in Taquari's Valley/RS. The approach relates to the impact of the PIBID in the initial training of the licensing according to the perceptions of the interviewed subjects' coordinators, who answered a semi open questionnaire. The discursive textual analysis methodology was employed in the data analysis, evidencing the positive aspects of the Program pertaining to the initial training and highlighting the teaching practice as seen through the activities developed by the scholarship holders in relation to the planning, the methodology and the acknowledging of differentiated realities of the involved school grounds, also pointing to the necessity of its continuity.
\end{abstract}

Keywords: Training. Teaching. PIBID. Scholarship. Graduation.

\section{INTRODUÇÃO}

Instituído pelo Ministério da Educação (MEC) por meio da Comissão de Aperfeiçoamento de Pessoal de Nível Superior (CAPES), o Programa Institucional de Bolsa de Iniciação à Docência (PIBID) vem se configurando como política pública de formação inicial e continuada de professores. O Programa foi lançado em 2007, visando apenas às universidades públicas federais. Mais tarde, em 2009, foi expandido para as estaduais e, em 2010, também para instituições municipais, comunitárias, confessionais e filantrópicas sem fins lucrativos (BRASIL, 2007; 2009; 2010).

Para aderir ao PIBID, conforme cronogramas pré-determinados, as Instituições de Educação Superior (IES) interessadas deveriam apresentar à CAPES um projeto de iniciação à docência de acordo com os editais de seleção vigentes. Vale ressaltar que, na última seleção, estavam aptas a se candidatar IES públicas e privadas, sem fins lucrativos, que ofertam cursos de licenciatura. As instituições com propostas aprovadas pela CAPES recebem cotas de bolsas e recursos financeiros, divididos em custeio e capital, para o desenvolvimento das atividades previstas no projeto institucional. Com relação à distribuição de bolsas, cabe enfatizar que os bolsistas são escolhidos mediante editais de seleção lançados pelas próprias IES.

No que tange às ações do PIBID dentro de cada IES selecionada, devem sempre prezar pelas metas do Programa em âmbito nacional. Nesse sentido, o Art. 4º, Seção II, Capítulo I, do Regulamento do Programa Institucional de Bolsa de Iniciação à Docência define os seguintes objetivos: 
I. incentivar a formação de docentes em nível superior para a educação básica;

II. contribuir para a valorização do magistério;

III. elevar a qualidade da formação inicial de professores nos cursos de licenciatura, promovendo a integração entre educação superior e educação básica;

IV. inserir os licenciandos no cotidiano de escolas da rede pública de educação, proporcionando-lhes oportunidades de criação e participação em experiências metodológicas, tecnológicas e práticas docentes de caráter inovador e interdisciplinar que busquem a superação de problemas identificados no processo de ensino e aprendizagem;

V. incentivar escolas públicas de educação básica, mobilizando seus professores como coformadores dos futuros docentes e tornando-as protagonistas nos processos de formação inicial para o magistério;

VI. contribuir para a articulação entre teoria e prática necessárias à formação dos docentes, elevando a qualidade das ações acadêmicas nos cursos de licenciatura; VII. contribuir para que os estudantes de licenciatura se insiram na cultura escolar do magistério, por meio da apropriação e da reflexão sobre instrumentos, saberes e peculiaridades do trabalho docente;

VIII. articular-se com os programas de formação iniciale continuada de professores da educação básica, de forma a contribuir com a criação ou com o fortalecimento de grupos de pesquisa que potencializem a produção de conhecimento sobre ensinar e aprender na Educação Básica;

IX. comprometer-se com a melhoria da aprendizagem dos estudantes nas escolas onde os projetos institucionais são desenvolvidos (BRASIL, 2016, p. 3-4).

As aproximações entre a universidade e a escola estão fortemente presentes nos objetivos do Programa. Elas vêm possibilitando avanços importantes na formação docente e consequentes mudanças no pensar e no fazer a licenciatura. Além disso, o PIBID tem sido um celeiro de atividades didático-pedagógicas e de metodologias de caráter inovador. As pesquisas de Gatti (2011) e Gatti et al. (2014), por exemplo, apontam os efeitos do Programa tanto na formação inicial quanto continuada dos docentes, no repensar os currículos dos cursos de licenciatura e na qualidade das ações desenvolvidas nas escolas parceiras, impactando a educação básica de maneira significativa.

Podem atestar esses impactos todos os envolvidos no Programa - coordenadores institucionais, coordenadores de área, supervisores, gestores, bolsistas e alunos das escolas parceiras. A Figura 1 ilustra a dinâmica do Programa no que diz respeito aos envolvidos. 


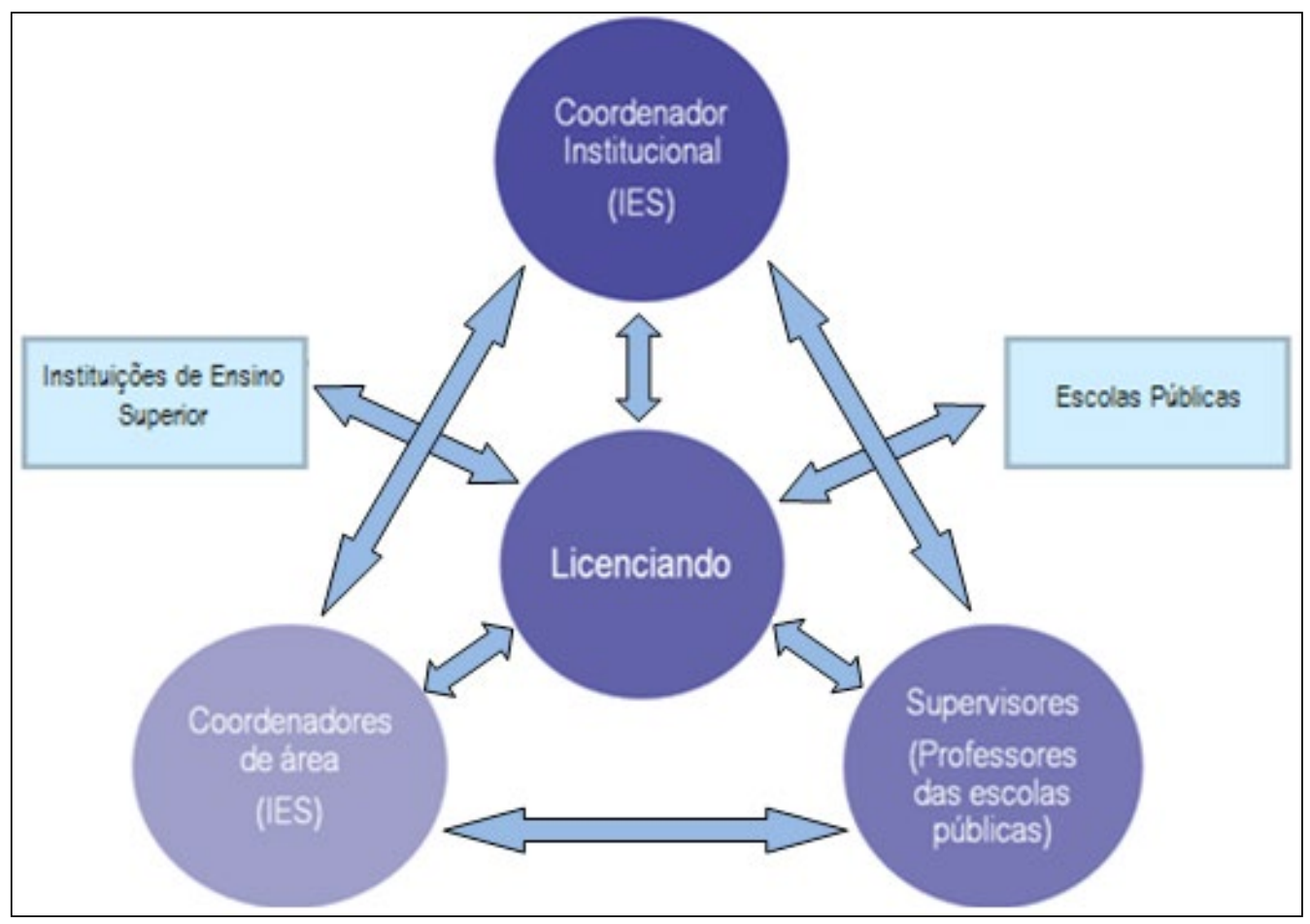

Fonte: Adaptada de Relatório de Gestão DEB - PIBID 2009/2011 (BRASIL, 2012, p. 29).

A Figura 1 demonstra de forma prática a organização do Programa e as suas inter-relações, evidenciando a participação tanto da escola quanto da universidade, que funcionam como o lócus de teorias e conhecimentos, e demonstra a peça chave, fundamental de todo o processo formativo, o estudante de licenciatura. Entendemos que esse é o ator principal e que os demais envolvidos são coadjuvantes no processo, sendo os cenários variados, principalmente quando se refere à escola, na sua diversidade e na sua particularidade, no seu contexto. Os licenciandos acabam por conhecer diversos cenários, pois realizam atividades em escolas diferentes e têm a oportunidade de se aproximar e atuar em realidades diferenciadas, fato que se destaca nas ações do Programa e constitui fator relevante se comparado aos estágios supervisionados da licenciatura, em que os estudantes acabam por, na maioria das vezes, conhecer a realidade de uma única escola.

Neste trabalho, buscamos investigar, a partir das percepções de um grupo de coordenadoras de área, quais são os impactos do PIBID na formação docente de estudantes de licenciatura de uma universidade comunitária do Sul do Brasil. Para tal, organizou-se uma pesquisa cujo recorte de parte dos resultados alimenta esta escrita. 


\section{METODOLOGIA}

$\mathrm{Na}$ construção de um projeto institucional alinhado com as normativas legais do PIBID estão inclusos vários sujeitos, como: coordenador institucional (professor de licenciatura que coordena o projeto PIBID na IES), coordenador de área (professor de licenciatura que coordena o subprojeto), supervisor (professor da escola pública de educação básica), e bolsista de iniciação à docência (estudante de licenciatura). A pesquisa a ser retratada neste artigo limita-se ao contexto de oito coordenadores de área do PIBID, que são docentes de licenciatura de uma universidade do Vale do Taquari/ RS.

Os dados aqui postos representam um recorte de uma investigação realizada por meio de um questionário, disponibilizado aos entrevistados via plataforma Google Drive. Trata-se de uma pesquisa com abordagem qualitativa, uma modalidade "voltada para o entendimento e a interpretação de fenômenos humanos, cujo objetivo é alcançar uma visão detalhada, complexa e holística destes" (FAZENDA; TAVARES; GODOY, 2015, p. 62). Sobre essa abordagem, Gerhardt e Silveira (2009, p. 31) complementam: "a pesquisa qualitativa não se preocupa com representatividade numérica, mas, sim, com o aprofundamento da compreensão de um grupo social, de uma organização, etc". Assim, entendemos que a abordagem qualitativa atende aos pressupostos da pesquisa em questão, pois há a preocupação com dados subjetivos que emergem das respostas dos sujeitos da pesquisa. Logo, as informações coletadas não são mensuradas e se trabalha com um grupo alvo, ou seja, os sujeitos estão em número reduzido. $\mathrm{O}$ intuito é identificar, via análise das respostas dos questionários, as informações relevantes quanto à atuação dos coordenadores de área, supervisores e bolsistas de iniciação à docência do grupo PIBID supracitado.

Para a investigação proposta foi utilizada a análise textual discursiva na perspectiva de Moraes e Galiazzi (2011), que visa à construção de metatextos analíticos com o objetivo de expressar os sentidos de um conjunto de textos lidos. Os metatextos se originam a partir da descrição e interpretação, representando a teorização dos fenômenos investigados. A qualidade dos textos, além da validade e confiabilidade, também é consequência dos argumentos do pesquisador enquanto autor (MORAES; GALIAZZI, 2011, p. 32).

A análise e a discussão dos dados, à luz da análise textual discursiva, foram organizadas a partir das respostas dadas às questões feitas aos sujeitos da pesquisa quanto aos impactos do PIBID na formação inicial dos bolsistas de Iniciação à Docência (ID), bem como no que diz respeito às experiências vivenciadas e às atividades desenvolvidas em sala de aula, corroborando com a importância do Programa na formação inicial. As categorias emergentes estão relacionadas à constituição do ser professor a partir da prática de sala de aula. Visando preservar a identidade dos sujeitos, fez-se uso de códigos: Coordenadora $1(\mathrm{C} 1)$, Coordenadora $2(\mathrm{C} 2)$ e assim sucessivamente. 


\section{A FORMAÇÃO PROFISSIONAL DOCENTE E O PIBID}

A formação do profissional docente está atrelada à prática de sala de aula. Nóvoa (2009) faz um comparativo da formação de professores (em nível de graduação e pósgraduação) com a de outras profissões (arquitetos, engenheiros, médicos). Nesse sentido, nos cursos de licenciatura das universidades, a tendência é:

[...] valorizar el papel de los científicos de la educación o de los especialistas pedagógicos y de su conocimiento teórico o metodológico en detrimento de los profesores y de su conocimiento práctico. Es innegable que la investigación científica en educación tiene una misión indispensable a cumplir, pero la formación de un profesor encierra una complejidad que sólo se obtiene a partir de la integración en una cultura profesional (NÓVOA, 2009, p. 211). ${ }^{6}$

Pensando nisso, e a partir das orientações das Diretrizes Curriculares Nacionais para os Cursos de Licenciatura (DCN/2015), muitos cursos de formação docente vêm reorganizando suas matrizes curriculares e ampliando as horas de estágio. Isso tem viabilizado um maior contato dos licenciandos com a realidade da escola, o que vai ao encontro da proposta de Nóvoa (2009) no tocante a uma formação docente construída dentro da profissão: “[...] insisto en la necesidad de devolver la formación de profesores a los profesores, porque el refuerzo de procesos de formación basados en la investigación solo tiene sentido si éstos se construyen dentro de la profesión" (NÓVOA, 2009, p. $211)^{7}$.

Porém, para além da teoria, vem se percebendo em inúmeros relatos que apenas reformulações curriculares não bastam. "Interessa um estágio que colabore decididamente na formação de profissionais que respondam às necessidades atuais da escola, e possam aprender juntamente com os professores que se encontram na ativa" (MASETTO, 2014, p. 13). Atualmente, aumentam-se as horas de estágio, os licenciandos se preparam para os momentos de observação, planejamento e prática didático-pedagógica, mas, na maioria das situações, não se inteiram do cotidiano escolar.

Em contrapartida, o PIBID vem possibilitando que os estudantes se insiram integralmente no contexto educacional e façam parte do ser e fazer da escola parceira cotidianamente, a partir dos diferentes projetos desenvolvidos. Esse estreito contato com a escola, aliado à orientação dos coordenadores de área e dos professores supervisores,

6 Tradução: “[...] valorizar o papel dos «cientistas da educação» ou dos «especialistas pedagógicos» e do seu conhecimento teórico ou metodológico em detrimento dos professores e do seu conhecimento prático. É inegável que a investigação científica em educação tem uma missão indispensável a cumprir, mas a formação de um professor encerra uma complexidade que só se obtém a partir da integração numa cultura profissional".

7 Tradução: “[...] insisto na necessidade de devolver a formação de professores aos professores, porque o reforço de processos de formação baseadas na investigação só faz sentido se eles forem construídos dentro da profissão". 
permite que os bolsistas de iniciação à docência adquiram experiência docente, além de outras habilidades inerentes à profissão.

Portanto, oportunizar que o licenciando vivencie o espaço escolar e atue nele ao longo da sua formação acadêmica desponta como uma exitosa possibilidade a partir das propostas do PIBID. Ao mesmo tempo, o bolsista passa a ter mais elementos e experiências para dar significado à sua formação docente. Nesse sentido, Ferreira (2014, p. 40) aponta que:

[...] os conhecimentos adquiridos nos cursos de formação (inicial/continuada) precisam imprimir em seus discentes características de uma formação que busque a teorização acadêmica, a criticidade, a reflexão sobre sua prática, a pesquisa como possibilidade para novos conhecimentos teórico-práticos diante dos enfrentamentos que a docência enfrenta na contemporaneidade. Os saberes não chegam prontos aos professores, eles precisam ressignificá-los de acordo com a realidade que permeia sua atividade docente.

Quando entendemos que o professor mobiliza uma ampla variedade de saberes, e que "os saberes oriundos da experiência de trabalho cotidiano parecem constituir o alicerce da prática e da competência profissionais" (TARDIF, 2014, p. 21), a aproximação com o ambiente escolar desde o início da formação do docente ganha relevância. No entanto, há de se ter cuidado para novamente não imprimir funções diferenciadas para as atividades realizadas na universidade em relação àquelas praticadas na escola. Por muito tempo, a dicotomia entre teoria e prática e a não valorização dos saberes produzidos na escola e pelos professores incentivaram a criação de um abismo entre os dois espaços:

Esse elemento ainda é resultado de um projeto curricular que prevê uma carga horária específica de atuação do aluno de licenciatura no espaço escolar, durante os estágios curriculares. No currículo da maior parte dos cursos, inclusive, denominase de carga horária prática da formação. Dessa estrutura disciplinar e dicotômica herdamos a percepção de que a escola é um espaço para praticar o que foi estudado na universidade (VOLKMER; HAUSCHILD; HERBER, 2017, p. 132).

Ao romper com essa separação, o PIBID configura-se como um espaço para refletir sobre a docência, ou seja, um espaço para a prática-reflexão formativa, ou uma docência praticada. Talvez aqui se perceba uma grande conquista do Programa.

Se hoje entendemos que "[...] a vivência prática tem pouco a oferecer se não for guiada por reflexão sistemática com investimento em leitura, documentação, pensamento e postura investigativa" (CARVALHO; PORTO, 2005, p. 16) e que os "conhecimentos escolares, pedagógicos, docentes e da prática profissional se misturam às características do professor diante de uma complexa atividade diária que o mesmo exerce com o objetivo de gerar ensino e aprendizagem" (FERREIRA, 2014, p. 40), são as vivências dos bolsistas no cotidiano escolar que permitem essa formação mais integral. Por isso, 
acreditamos que o papel que deve exercer o professor não pode ser reduzido a meras explicações de conteúdos e, muito menos, a avaliação de resultados. É preciso repensar a prática na busca da superação de um modelo tradicional, fragmentador e técnico, conduzindo à implantação de uma visão mais holistica, isto é, uma proposta de Educação e de formação de professores mais abrangente, reflexiva e dialógica. (FLORENTINO; RODRIGUES, 2015, p. 62).

Nesse sentido, acredita-se que a inserção no PIBID oportuniza a esses bolsistas o rompimento de percepções ainda presentes no mundo da universidade e uma crescente valorização dos saberes escolares, das experiências e das reflexões cotidianas.

A prática pedagógica entendida como o fazer diário do professor subsidia a interrelação entre a teoria e a prática, associação que está interligada em uma rede de conhecimento na qual os conhecimentos formais, não formais e os informais se conectam criando possibilidades de ensinar e aprender (FERREIRA, 2014, p. 40).

Também merece destaque o fato de o Programa fomentar momentos que promovam reflexões e discussões sobre variadas questões relativas à docência por meio de rodas de formação frequentes, seminários integradores, seminários institucionais, os quais são de suma importância para a qualificação da formação docente dos acadêmicos dos cursos de licenciatura e dão sustentação aos trabalhos desenvolvidos nas escolas parceiras. Essa postura está alicerçada nas considerações de Nóvoa (1992, p. 28), para quem:

\footnotetext{
[...] a formação passa pela experimentação, pela inovação, pelo ensaio de novos modos de trabalho pedagógico. E por uma reflexão crítica sobre a sua utilização. A formação passa por processos de investigação, diretamente articulados com as práticas educativas.
}

De forma resumida, a relevância que o PIBID assume na formação profissional docente fica evidenciada em diferentes aspectos, como "revitalização de cursos de licenciatura com a permanência dos estudantes nos cursos, o crescimento significativo da interlocução entre as IES, as escolas de educação básica e as comunidades a elas vinculadas, assim como uma efetiva qualificação da formação docente inicial e continuada" (CARTA DE CURITIBA, 2016, texto digital). Diante disso, vale imergir numa análise mais específica, buscando inferir alguns impactos das ações pibidianas na visão de profissionais do magistério diretamente ligados ao Programa.

\section{OS IMPACTOS DO PIBID DE ACORDO COM AS PERCEPÇÕES DE UM GRUPO DE COORDENADORAS DE ÁREA}

Muitas pesquisas vêm apontando os impactos do PIBID, tendo em vista a diversidade de ações desenvolvidas pelos bolsistas em escolas públicas de educação 
básica em âmbito nacional. Para exemplificar as atividades pibidianas, especificamente no Projeto Institucional (2014, texto digital) da IES foco desta escrita, podemos citar:

\begin{abstract}
I - estudo do contexto educacional [...];
II - desenvolvimento de ações que valorizem o trabalho coletivo, interdisciplinar e com intencionalidade pedagógica clara para o processo de ensino-aprendizagem; III - planejamento e execução de atividades nos espaços formativos [...];

IV - participação nas atividades de planejamento do projeto pedagógico da escola, bem como participação nas reuniões pedagógicas;

$\mathrm{V}$ - análise do processo de ensino-aprendizagem [...];

VI - leitura e discussão de referenciais teóricos contemporâneos educacionais para o estudo de casos didático-pedagógicos;

VII - cotejamento da análise de casos didático-pedagógicos com a prática e a experiência dos professores das escolas de educação básica, em articulação com seus saberes sobre a escola e sobre a mediação didática dos conteúdos;

VIII - desenvolvimento, testagem, execução e avaliação de estratégias didáticopedagógicas e instrumentos educacionais, incluindo o uso de tecnologias educacionais e diferentes recursos didáticos;

IX - elaboração de ações no espaço escolar a partir do diálogo e da articulação dos membros do programa, e destes com a comunidade;

$\mathrm{X}$ - sistematização e registro das atividades em portfólio ou instrumento equivalente de acompanhamento;

XI - desenvolvimento de ações que estimulem a inovação, a ética profissional, a criatividade, a inventividade e a interação dos pares (PROJETO INSTITUCIONAL, 2014).
\end{abstract}

Esse aporte qualitativo presente nas diferentes ações, na visão dos sujeitos da pesquisa, está atrelado aos possíveis impactos do Programa. Conforme C2, "o contato com a sala de aula, desde muito antes da aplicação dos estágios é [...] um dos principais impactos para a formação inicial dos licenciandos". Nessa perspectiva, é perceptível que as contribuições na formação docente estão relacionadas com as vivências na escola e a imersão no contexto escolar desde o início do curso de licenciatura.

A apropriação das relações estabelecidas na escola também foi apontada como um dos impactos. Para $\mathrm{C} 1$, os bolsistas "adquirem segurança na docência", tendo em vista que "as vivências in loco possibilitam o desenvolvimento da concep̧̧ão de que a prática docente envolve uma série de habilidades, que vão muito além do conhecimento da teoria e de capacidade de elaboração de planos de aula" (C2). Esse entendimento do ser professor fica evidente também nas aulas dos cursos de licenciatura, pois os pibidianos têm como diferencial o fato de conhecerem a realidade da escola e passarem, na maioria das vezes, por diversos contextos: "Os pibidianos chegam aos estágios e à sala de aula, na condição de professores titulares, conhecedores do que é ser professor e ricos em experiências quanto ao processo pelo qual se passa até chegar ao dar uma aula" (C3).

Também se identifica um desenvolvimento no que diz respeito ao manejo de sala de aula e ao gerenciamento de situações as mais diferenciadas possíveis. A partir disso, os bolsistas são levados a refletir e replanejar, a fim de qualificar a prática. É o que vem ocorrendo em situações de indisciplina, quando os próprios bolsistas identificam, com 
base no envolvimento dos estudantes da educação básica, que a atividade planejada não atingiu os objetivos pretendidos. Esse repensar a prática e ter a possibilidade de avaliar, reorganizar e fazer novamente é possivel a partir do PIBID.

Assim, à medida que o tempo passa, os bolsistas evidenciam maior entendimento de questões relacionadas à sala de aula, o que reflete nas suas ponderações acerca das experiências angariadas no cotidiano escolar e nas suas ações, tanto como estudantes de licenciatura quanto como docentes das escolas parceiras. Nesse sentido, C4 aponta que, "ao longo das vivências, percebe-se maior engajamento e motivação [dos bolsistas] em relação à sua formação docente". Essa postura dos bolsistas de iniciação à docência faz com que "aspectos como insegurança e receio em relação às práticas desenvolvidas na sala de aula sejam transformados já nos primeiros meses de atuação no projeto" (C4).

Ainda para C4, "está havendo muita conscientização sobre o papel do professor na sala de aula e sobre a importância do planejamento, de saber para onde ir, ou seja, estabelecer objetivos claros". No que diz respeito ao planejamento, C5 identifica que o "maior impacto está em aprender a planejar uma prática pedagógica que visa romper com a fragmentação dos conbecimentos", e C6 complementa: "os bolsistas se dão conta de que é imprescindivel ter mais dominio de conteúdo".

Essa reflexão sobre a prática é parte fundamental do fazer docente, posto que

[...] o que se precisa é possibilitar, que, voltando-se sobre si mesma, através da reflexão sobre a prática, a curiosidade ingênua, percebendo-se como tal, se vá tornando crítica. [...] a prática docente crítica, implicante do pensar certo, envolve o movimento dinâmico, dialético, entre o fazer e o pensar sobre o fazer (FREIRE, 2001, p. 42-43).

É evidente, portanto, que o PIBID representa reais ganhos em termos de vivências escolares, experiências pedagógicas e capacidade de lidar com situações as mais variadas. Essa estreita relação entre academia e escola é extremamente salutar e tem se mostrado muito eficaz na discussão de ações efetivas em educação, na reflexão sobre a prática pedagógica e no seu aprimoramento. C6 aponta justamente para essa constatação ao considerar que:

a inserção dos licenciandos no cotidiano da escola parceira, vivenciando a realidade da rede pública de educação e experimentando atuaçôes docentes inovadoras, que estimulam a inserção tecnológica e o desenvolvimento de atividades interdisciplinares, que prezam pela relação teoria-prática e que, acima de tudo, estejam contribuindo no processo de ensino-aprendizagem, são alguns objetivos do PIBID que, com certeza, vêm impactando na formação inicial dos bolsistas ID.

Por fim, o PIBID não é uma panaceia educacional, mas sim um Programa que vem se firmando cada vez mais como uma proposta para a educação que, dentre as várias contribuições, destaca-se pelo contato direto com a realidade escolar, possibilitando aos bolsistas desenvolver um perfil diferenciado dos demais licenciandos, proporcionando 
reflexões constantes sobre a prática docente e estimulando a valorização de atitudes crítico-reflexivas no processo de autoformação.

\section{CONSIDERAÇÕES FINAIS}

O contexto abordado nesta escrita permite reforçar que as ações do PIBID são de grande importância, pois incentivam os licenciados a permanecerem na docência. A inserção no cotidiano da escola parceira tem permitido que os acadêmicos vivenciem a realidade da rede pública de educação e experimentem atuações docentes inovadoras, que estimulam a inserção tecnológica e o desenvolvimento de atividades interdisciplinares, que prezam pela relação teoria-prática e que, acima de tudo, estejam contribuindo no processo de ensino-aprendizagem. Esses são alguns dos objetivos do Programa que, com certeza, vêm impactando na formação inicial dos bolsistas de iniciação à docência.

As coordenadoras identificam também como impacto os obstáculos vencidos no fazer cotidiano desse professor que está em processo de formação, pois a mudança de comportamento tanto no que diz respeito à responsabilidade e desenvoltura em sala de aula, quanto nos diálogos estabelecidos entre seus pares, aprimora-se a cada dia. Aspectos relacionados à insegurança e receio quanto às práticas desenvolvidas são transformados, segundo C7, já nos primeiros meses de atuação no Programa.

Ao que tudo indica, o PIBID vem fortalecendo substancialmente o diálogo entre as Instituições de Educação Superior (IES) e as Instituições de Educação Básica, o que certifica, mais uma vez, o Programa como política pública de formação inicial docente que contribui, de maneira significativa, com a qualidade da educação brasileira.

\section{REFERÊNCIAS}

BRASIL. Ministério da Educação. Portaria 38, de 12 de dezembro de 2007. Dispõe sobre o Programa de Bolsa Institucional de Iniciação à Docência - PIBID para instituições federais de ensino superior - IFES. Diário Oficial da União, Brasília, DF, 13 de dezembro de 2007. Disponível em: <www.cmconsultoria.com.br/imagens/diretorios/diretorio14/arquivo1003. pdf $>$. Acesso em: 15 jan. 2013.

. Ministério da Educação. Edital CAPES no 2/2009. Amplia o Pibid para instituições federais e estaduais de ensino superior. Diário Oficial [da] República Federativa do Brasil, Brasília, DF, 25 de setembro de 2009. Disponível em: <www.capes.gov.br/images/ stories/download/bolsas/Edita102_PIBID2009.pdf>. Acesso em: 15 jan. 2013.

Ministério da Educação. Edital CAPES n⿳0 18/2010. Convite para Editais Pibid provenientes de instituições públicas municipais e comunitárias, confessionais e filantrópicas sem fins lucrativos. Diário Oficial [da] República Federativa do Brasil, Brasília, DF,13 abr. 2010a. Disponível em: <www.capes.gov.br/images/stories/download/bolsas/Edital18_ PIBID2010.pdf >. Acesso em: 15 mar. 2013. 
. Ministério da Educação. Relatório de Gestão 2009-2011 DEB. 2012. Disponível em: <www.CAPES.gov.br/images/stories/download/bolsas/DEB_RelatorioFinalGestao-2009-2011.docx>. Acesso em: 20 mar. 2013.

. Conselho Nacional de Educação. Define as Diretrizes Curriculares Nacionais para a formação inicial em nível superior (cursos de licenciatura, cursos de formação pedagógica para graduados e cursos de segunda licenciatura) e para a formação continuada. Resolução CNE/CP n. 02/2015, de $1^{\circ}$ de julho de 2015. Brasília, Diário Oficial [da] República Federativa do Brasil, seção 1, n. 124, p. 8-12, 02 de julho de 2015. Disponível em: <http://pesquisa.in.gov.br/imprensa/jsp/visualiza/index.jsp?data=02/07/2015\&jornal=1\& pagina $=8 \&$ total Arquivos $=72>$. Acesso em: 10 jan. 2018 .

Coordenação de Aperfeiçoamento de Pessoal de Nível Superior (CAPES). Portaria No 46, de 11 de abril de 2016. Aprova o Regulamento do Programa Institucional de Bolsa de Iniciação à Docência (PIBID). Disponível em: <www.capes.gov.br/images/stories/download/ legislacao/15042016-Portaria-46-Regulamento-PIBID-completa.pdf>. Acesso em: 10 jan. 2018 .

CARTA DE CURITIBA. VI Encontro Nacional das Licenciaturas (ENALIC), o V Seminário Nacional do PIBID, o IV Encontro Nacional de Coordenadores do PIBID e o X Seminário Institucional PIBID PUC-PR. Anais, 2016. Texto digital. Disponível em: <www. unioeste.br/eventos/enalic/anais>. Acesso em: 10 jan. 2018.

CARVALHO, M. J.; PORTO, L. O que é portfólio educacional. In: Portfólio Educacional: proposta alternativa de avaliação. Porto Alegre: UFRGS, 2005, p.11-33.

FAZENDA, I. C. A.; TAVARES, D. E.; GODOY, H. P. Interdisciplinaridade na pesquisa científica. Campinas, SP: Papirus, 2015.

FERREIRA, J. L. A complexa relação entre teoria e prática pedagógica na formação de professores. In: FERREIRA, J. L. (org.). Formação de professores: teoria e prática pedagógica. Petrópolis: Vozes, 2014, p. 33-49.

FLORENTINO, J. A.; RODRIGUES, L. P.. Disciplinaridade, interdisciplinaridade e complexidade na educação: desafios à formação docente. Educação Por Escrito. Porto Alegre, v. 6, n. 1, jan-jun 2015, p.54-67.

FREIRE, P. Pedagogia da autonomia: saberes necessários à prática educativa. 20 ed. São Paulo: Paz e Terra, 2001.

GATTI, B. A. (Org.) Políticas docentes no Brasil: um estado da arte. Brasília: UNESCO, 2011.

GATTI, B. A.; ANDRE, M. E. D.; GIMENES, N. A. S.; FERRAGUT, L. Um estudo avaliativo do Programa Institucional de Bolsa de Iniciação à Docência (PIBID). Coleção Textos FCC, v. 41, p. 4-117, 2014. Disponível em: <www.capes.gov.br/images/stories/ download/bolsas/24112014-pibid-arquivoAnexado.pdf>. Acesso em: 02 set. 2016.

GERHARDT, T. E.; SILVEIRA, D. T. (Org.). Métodos de pesquisa. Porto Alegre: Ed. da UFRGS, 2009. (Educação a Distância, 5). 
MASETTO, M. T. Desafios para a docência no ensino superior na contemporaneidade. XVII Encontro Nacional de Prática de Ensino - ENDIPE, 2014. $\boldsymbol{E}$-book. Disponível em: <www.uece.br/endipe2014/ebooks/livro4/48.\%20DESAFIOS\%20PARA\%20 A\%20DOC\%C3\%8ANCIA\%20NO\%20ENSINO\%20SUPERIOR\%20NA\%20 CONTEMPORANEIDADE.pdf $>$. Acesso em: 08 dez. 2017.

MORAES, R.; GALIAZZI, M. C. Análise textual discursiva. 2.ed. rev. Ijuí: Ed. Unijuí, 2011.

NÓVOA, A. Formação de professores e formação docente. In: Os professores e sua formação. Lisboa: Dom Quixote, 1992.

Para una formación de profesores construida dentro de la profesión. Revista de Educación, 350. Septiembre-diciembre 2009, pp. 203-218. Disponível em: <www.mecd.gob. es/dctm/revista-de-educacion/articulosre350/re35009.pdf?documentId=0901e72b81234820 >. Acesso em: 04 dez. 2017.

PROJETO INSTITUCIONAL. 2014. Texto digital. Disponível em: <www.univates.br/ pibid/pibid-univates>. Acesso em $18 \mathrm{dez} .2017$.

TARDIF, M. Saberes docentes e formação profissional. 16.ed. Petrópolis: Vozes, 2014.

VOLKMER, M.; HAUSCHILD, C. A.; HERBER, J. Por uma docência praticada: a Universidade, a Escola e a Formação do Professor. In: HAUSCHILD, C. A. et al. (Coords.).

Anais do II Congresso Internacional de Ensino e Aprendizagens, VI Seminário Institucional do PIBID Univates e III Seminário Observatório da Educação Univates: formação de professores e educação básica. Lajeado: Ed. da Univates, 2017. p. 132-133. Disponível em: <www.univates.br/editora-univates/media/publicacoes/212/pdf_212.pdf>. Acesso em: 07 fev. 2018. 